\title{
Nonsyndromic Aplasia Cutis Congenita: a Case Report
}

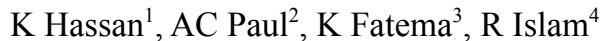

\begin{abstract}
:
Nonsyndromic aplasia cutis congenita is a condition in which babies are born with localized areas of missing skin. These areas resemble ulcers or open wounds, although they are sometimes already healed at birth. Lesions most commonly occur on the top of the head (skull vertex). In some cases, the bone and other tissues under the skin defect are also underdeveloped. If the baby is born by cesarean section, then the patient's attendants recognize the wound as an injury which might be performed by the surgeon at the time of cesarean section. We are reporting this type of a case whose father attempted to take legal procedure against the surgeon, but finally he understood that this was a congenital disease of his baby.
\end{abstract}

Key words : ACC, Aplasia Cuties, J-B syndrome, A-O syndrome.

\section{Introduction :}

Nonsyndromic aplasia cutis congenita is a condition in which babies are born with localized areas of missing skin. These areas resemble ulcers or open wounds, although they are sometimes already healed at birth. Lesions most commonly occur on the top of the head (skull vertex). In some cases, the bone and other tissues under the skin defect are also underdeveloped. When the underlying bone and other tissues are involved, affected individuals are at higher risk of infections. If these severe defects occur on the head, the membrane that covers the brain (the dura mater) may be exposed, and life-threatening bleeding may occur from nearby vessels ${ }^{1}$.

Aplasia cutis congenita affects approximately 1 in 10,000 newborns. The incidence of the nonsyndromic form is unknown. There is no racial or sexual predilection $^{2}$.

1. Dr. Md. Kamrul Hassan, MBBS, MS (Pediatric Surgery), Associate Professor \& Head, Department of Pediatric Surgery, Faridpur Medical College, Faridpur.

2. Dr. Amal Chandra Paul, MBBS, MS (Pediatric Surgery), Associate Professor, Department of Pediatric Surgery, Faridpur Medical College, Faridpur.

3. Dr. Kaneez Fatema, MBBS, MS (Gynae \& Obs.), Assistant Professor, Department of Gynae \& Obs, Faridpur Medical College, Faridpur.

4. Dr. Md. Raisul Islam, MBBS, Assistant Registrar, Department of Pediatric Surgery, Faridpur Medical College Hospital, Faridpur.

Address of correspondence :

Dr. Md. Kamrul Hassan, MBBS, MS (Pediatric Surgery), Associate

Professor \& Head, Department of Pediatric Surgery, Faridpur

Medical College, Faridpur. Phone: +88-01711 440 443,

Email: khassanb17@gmail.com
Most affected babies have a single lesion. The lesions vary in size and can be differently shaped: some are round or oval, others rectangular, and still others starshaped. They usually leave a scar after they heal. When the scalp is involved, there may be an absence of hair growth (alopecia) in the affected area ${ }^{1,2}$. The exact cause is not known. Genetic factors, teratogens, compromised vasculature to the skin, trauma are all implicated.

Skin lesions are typically the only feature of nonsyndromic aplasia cutis congenita, although other skin problems and abnormalities of the bones and other tissues occur rarely. However, the characteristic skin lesions can occur as one of many symptoms in other conditions, including Johanson-Blizzard syndrome and Adams-Oliver syndrome ${ }^{3,4}$.

\section{Case report :}

A 2 days old female baby was admitted in Pediatric Surgery ward of Faridpur Medical College Hospital with an ulcerated area on the scalp. The baby was born by cesarean section in a private hospital 2 days back. The baby was apparently well after birth. But mother of the baby recognize that there is an ulcerated area at middle part of the scalp. The parents complained that the surgeon had cut the scalp of the baby at the time of cesarean section.

Examination revealed that there is a healing ulcer on the occipital region of the scalp, about $2 \mathrm{~cm}$ in diameter, floor was healthy, margin was sloping, and totally absence of hair (Fig.1). 


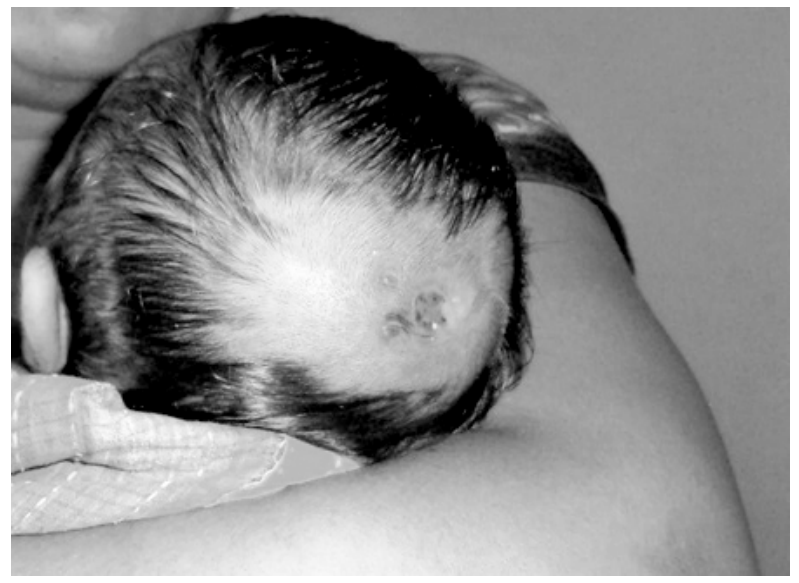

Figure-1: Skin lesion on the vertex of scalp.

\section{Discussion :}

Nonsyndromic aplasia cutis congenita can have different causes, and often the cause is unknown. Because the condition is sometimes found in multiple members of a family, it is thought to have a genetic component; however, the genetic factors are not fully understood. Researchers suggested that genes important for skin growth may be involved. It is thought that impairments of skin growth more commonly affect the skin at the top of the head because that region needs to be able to grow quickly to cover the fast-growing skull of a developing baby ${ }^{5}$.

In some cases, nonsyndromic aplasia cutis congenita is caused by exposure to a drug called methimazole before birth. This medication is given to treat an overactive thyroid gland. Babies whose mothers take this medication during pregnancy are at increased risk of having the condition. In addition, certain viral infections in a pregnant mother can cause the baby to be born with the skin lesions characteristic of nonsyndromic aplasia cutis congenita. Other cases are thought to be caused by injury to the baby during development ${ }^{5-7}$.

Most cases of nonsyndromic aplasia cutis congenita are sporadic, which means they occur in people with no history of the disorder in their family. When the condition runs in families, inheritance usually follows an autosomal dominant pattern, which means one copy of an altered gene in each cell is sufficient to cause the disorder. Rarely, the condition appears to follow an autosomal recessive pattern of inheritance, which means both copies of a gene in each cell have mutations ${ }^{7}$. The parents of an individual with an autosomal recessive condition each carry one copy of the mutated gene, but they typically do not show signs and symptoms of the condition.

\section{Conclusion :}

Nonsyndromic Aplasia Cutis Congenita is an uncommon disease which often may need surgical repair. After each delivery every neonate should be searched thoroughly for any congenital defect and communicate properly with the patients party as well as referred the patient to respective department in due time.

\section{References :}

1. Kruk JJ, Janik J, Raykala T. "Aplasia cutis congenital of the scalp, Report of 16 cases" Dermatology. Surg. 1998; 24(5):549-53.

2. Joseph GM. Cutaneous Defects. In: Nelson Textbook of Pediatrics, Kliegman, 18th edition. Philadelphia, PA: Saunders Elsevier; 2012, 2220-2222.

3. Chitnis MR, Carachi R, Galea P. "Familial Aplasia Cutis Congenita", Eur. J. Pediatric Surg. 1996;6(2):100-1.

4. Anderson CE, Hollister D, Szalay GC. Autosomal dominantly inherited cutis aplasia congenita, ear malformations, right-sided facial paresis, and dermal sinuses. Birth Defects Orig. Art. Ser. 1979; XV(5B): 265-70.

5. Elliott AM, Teebi AS. Further examples of autosomal dominant transmission of nonsyndromic aplasia cutis congenita. (Letter) Am. J. Med. Genet.1997;73:495-96.

6. Evers MEJW, Steijlen PM, Hamel BCJ. Aplasia cutis congenita and associated disorders: an update. Clin. Genet. 1995;47:295-301.

7. Gnamey DK, Koffi KS, Nagalo K, Guedenon KM, AkakpoNumado GK, Balaka B et al. Aplasia cutis congenita associated with Goltz syndrome in a male neonate. Genet. Counsel. 2010; 21:41-47. 